\title{
Analyzing the Impact of Different Transport Governance Strategies on Climate Change
}

\author{
Shengrun Zhang ${ }^{1(\mathbb{D})}$ and Frank Witlox $1,2,3, * \mathbb{C}$ \\ 1 College of Civil Aviation, Nanjing University of Aeronautics and Astronautics, Nanjing 210016, China; \\ zhangshengrun@nuaa.edu.cn \\ 2 Department of Geography, Ghent University, 9000 Gent, Belgium \\ 3 Department of Geography, University of Tartu, 50090 Tartu, Estonia \\ * Correspondence: Frank.Witlox@UGent.be
}

Received: 20 November 2019; Accepted: 23 December 2019; Published: 25 December 2019

\begin{abstract}
The transport industry is one of the few sectors in which emissions continue to grow, contributing $26 \%$ to the global $\mathrm{CO}_{2}$ emissions. Transport agencies everywhere in the world are focusing on mitigation strategies to reduce greenhouse gas emissions. Policy-makers are under pressure to tackle the issue of climate change and approach sustainable transport by promoting more sustainable practices and altering behavior. This paper attempts to explore the impact of transport on climate change through the lens of governance by establishing a systematic review framework. The results showed that developing nations should be influential in managing their public transport agencies to achieve economic transformation. They require a functional, reliable, and effective transport system and these can only be derived by properly formulated and implemented policies with the aid of all relevant private, academic, and government bodies working together. This study concluded that developing nations need to manage their pricing methods, using them to facilitate transport systems that are unlikely to affect the climate. To this end, transport policy and governance need to be reviewed to take into account climate change and natural disaster concerns. Additionally, guidelines and strategies should be proposed for every actor involved, i.e., transport community, top-level leaders, and all governmental levels and private sectors.
\end{abstract}

Keywords: multi-level transport governance; greenhouse effect; climate change; governance; sustainable development; mitigation

\section{Introduction}

Transportation and being mobile plays a vital role in everyday life [1,2]. Efficient human and goods movement is an essential part of any productive economy and is vital for social cohesion, welfare creation, and improved health and well-being [3-5]. Investment or political intervention in the transport system thus supports or addresses other broader objectives, such as climate change or congestion [3]. The transport sector not only accounts for a fifth of world greenhouse gas emissions but also shows a faster rise in emissions than any other industries [5]. Transport authorities around the world focus on greenhouse gas emission mitigation strategies [6]. The most important mitigation strategies follow from improving overall transport efficiency. These are material replacement, reduction in aerodynamic drag, better automatic transmissions, reducing engine friction, variable valve timing, direct injection stratified charge (DISC) gasoline engines, turbocharged DI diesel engines, advanced tires, hybrid electric powertrains, and proton exchange membrane (PEM) fuel cell powertrains [7]. Still, the transport sector is the domain from which reducing emissions has faced greater difficultly and actions at all levels of government-from international to local—will be necessary to make significant progress in the future. In terms of the contribution of the transport sector to climate change, the 
activities of formal institutions as well as individuals and organizations are strongly affected [8]. Many studies suggest that both cleaner vehicles and mobility management approaches in the transport sector are needed to achieve energy conservation and emission reduction goals [8-10]. Nonetheless, most emission reduction analyses are biased towards mobility management because they overlook or find only a limited number of potential strategies. Moreover, current analysis generally ignores the additional external costs derived from increased fuel efficiency of vehicles and subsidized alternative fuels encouraging additional vehicle travel, called a rebound effect [9]. Another reason is that the current analysis finds the reduction of emissions from mobility management difficult to predict [10].

Today, climate change, which is directly or indirectly attributed to human activities, can be considered as one of the largest threats to the planet [2,9]. Climate change impacts also threaten future developments, particularly in areas where poverty is widespread and where key resources, such as infrastructure, are underdeveloped to meet current needs [10,11]. Climate change is an important challenge that can have significant effects on natural resources [12], different communities, and patterns of life for present and future generations $[8,13,14]$.

Related to economic growth, the transport sector plays a key role as economic activities accelerate the surge of demand for transport and satisfies the needs of both cargo and passengers. The same holds true for the opposite relation, but all comes at a cost. Nearly $95 \%$ of energy used in transport is derived from the use of high-carbon oil-based fuels. The contribution of light-duty vehicles (LDVs) alone to emissions is estimated to be $44.5 \%$. LDVs are 'mobile machines' that are primarily used to transport passengers and cargo. As the number of LDVs increases in many developing countries due to urbanization, shared mobility is becoming more effective. These changes are attributable to the impact of technology, ease of access, and economics and policy measures on human behavior. In emerging economies, notwithstanding some indications of early peak scenarios, the use and purchase of personal vehicles is increasing due to economic stability, higher welfare, and a continuous population growth, which will lead to more $\mathrm{CO}_{2}$ emissions [2]. Climate change is also one of the world's most prominent political issues (with a strong divide between believers and non-believers [8]). It is certainly a more ambitious effort to assess the performance of municipalities as a whole instead of focusing on each public service individually (e.g., water services, waste management, urban transport, etc.). According to da Cruz and Marques (2014) [15], although social, environmental, and economic perspectives in the transport sector are necessary, they are not sufficient to provide a benchmark for local governments. In the last decade, the argument that the performance of all organizations must be seen through these three (often conflicting) lenses has gained traction in both academic and professional settings. Indeed, while achieving good governance (GG) may not be an end in itself, it is certainly instrumental and necessary to maintain the pillars of sustainability. Governance concerns the behavior of institutions, governance processes, and relations between the state, citizens, and other stakeholders, and GG requires a high level of public involvement in policy-making, accountability, transparency, and respect for the rule of law [15]. According to the above-mentioned argument, this paper presents the literature context of the transport sector and its contributions to climate change through the examination of the governance of transport. In order to arrive at a first understanding of the impact of transport on climate change, this paper provides a basis using the current literature on good governance to investigate its effects with the transport sector. This approach is chosen because the paper seeks to present an analytical step towards a deeper acknowledgment of the impact of transport on climate change. The aim is to stimulate a growing stream of research on exploring the relationship between the governance of the transport sector and the role of good transport governance in the climate change.

This study is conducted based on a comprehensive literature review to investigate the impact of transport on climate change through a governance lens by establishing a systematic review framework. Accordingly, the objective of this paper is to review the impact of transport on climate change and to answer how it should be governed efficiently and effectively. The novelty of the current study is two-fold: (i) it highlights the impact of transport governance on climate change; and (ii) it addresses the effectiveness of transport for better climate mitigation. To be clear, this study contributes to assessing 
the key policy levels for change and considers transport governance issues linked with climate change impacts. The ultimate aim of this review study is to provide policy-makers with a realistic knowledge and understanding on how to establish different modules of transport governance at different levels, which can result in practical interventions toward climate change. This can be formulated into a more straightforward research question, which is: How does poor or GG affect climate change? Additionally, what are the best and effective policies for adapting to climate change impacts?

The rest of this paper is organized as follows: Section 2 provides an overview on governance in terms of its general concept and two forms (good vs. poor governance). The application of general governance into transport industry is then introduced. Importantly, this section also elaborates on how transport governance affects climate change. Section 3 pinpoints the key problems existing in the relationship between transport and climate change. Section 4 reviews existing transport policies that intend to enhance the efficiency of the system for a better climate mitigation, followed by Section 5 where we discuss our findings and their main implications. The final section summarizes our major findings and provides a few suggestions for further research directions.

\section{Governance Overview}

\subsection{What Is Governance?}

The concept of governance is not new [16]. It has played an important role in contemporary discussions in social sciences and especially in public administration at the end of the 20th and the beginning of the 21st centuries. One of the main reasons why the concept became increasingly popular is its capacity to cover the entire spectrum of institutions and relations involved in the governance process, in contrast with the narrower term "government" [17-19]. In that sense, the tradition and the agencies through which authority is exercised for the common good in a country are also considered to be part of governance [20]. The concept of "governance" [21] is notoriously complex and is applied to the decision-making processes. It is a multi-level and broad concept which works on all social levels, such as households, villages, towns, nations, regions, or the world [22].

\subsection{Good vs. Poor Governance}

In the 1990s, the notion of GG emerged in view of a failure of adjustment policies and the development of new policies to enhance more efficient government strategies $[18,20]$. Promotors of this GG paradigm were the World Bank, the United Nations Development Programme (UNDP), and many other major international players. GG arises when resources are allocated and managed to address collective problems. That is, when a state effectively supplies its citizens with the quality required for public goods. One aspect of GG thus relates to accountability, forcing the state to focus on clear goals, effective policies, and implementing policies of surveillance and reporting mechanisms. In a study by Beshi and Kaur (2019) [22] in Ethiopia, which selected Bahir Dar City, it was estimated that the perceived accountability practices would significantly influence public confidence in local government. The results have shown that the perceived responsibilities affect the public's trust in local government considerably. Thus, in a way GG practices will restore and strengthen public confidence in local government.

A natural challenge for organizations is to try to overcome their failures and develop strategies to increase efficiently. To address these challenges, Beshi and Kaur (2019) [22] have formulated a number of principles: firstly, countries can be regarded as unlimited, connected, and locally-, nationally-, or internationally connected. Secondly, rural space and scale are developing with an ongoing pace, so it is not acceptable to have a strict idea of scale or space. Thirdly, the wave of land governance means that there are different spaces in global processes that can be looked at $[18,19]$. In view of these guidelines, what does good administration mean? [21,23]. GG is an active and productive state/citizens cooperation [19] and the key to its success lies in participating [24]. Through GG, equality between 
men and women is promoted, the environment is protected, individual liberties are exercised, and tools are provided to reduce poverty, privation, fears, and violence $[22,25,26]$.

GG contrasts with bad or poor governance (PG). PG means that the organization cannot effectively manage resources and resolve the conflict between employees and stakeholders. PG is becoming more pronounced in the context of government when the country or government does not meet society's needs even if it uses the best available resources. PG is also a contagious symptom of institutional failures and failures in leadership. PG in society had many adverse aspects on the economic as well as political, social and cultural domain. PG negatively affects countries' growth rates. PG has been found to reduce investment, thus reducing growth and development rates [16,27].

\subsection{Governance of Transport: Definitions and Approaches}

Transport governance (TG), in line with the general governance debate, has also received increasing attention from scholars in numerous disciplines and with respect to many transport-related activities [21]. Here, the term refers to the political and legal structures and mechanisms used for managing and coordinating transport systems, their interrelationships, and the allocation of resources [28]. Firstly, it is worth mentioning the multi-level governance (MLG) perspective, which accounts for the fact that governance activities occur at different levels (local, national, supranational). Actions at one level can alter the boundary conditions of actors at other levels, thereby creating a dynamic that is hard to control [29]. There is a need for the implementation of a MLG framework and the types of analytical framework for complex policy objectives that go beyond geographical, administrative, and national/supra-national scopes and mandates for action [21,30]. MLG has been built in the theoretical approach to policy development, implementation, effectiveness and accountability.

It is not founded on the premises that national governments are the primary political entity and that decision-making takes place within a clustered centralized array (international, domestic, federal, sub-regional, and local) of governments. Public transport is supported by governments to deliver social and environmental goals through the establishment of public value for its inhabitants and visitors through the instrument of a subsidized transport service. MLG literature has evolved from an attempt to understand the MLG issues faced by federal (USA) and supranational (European Union) governments to include interactions between government levels and smaller municipalities in a specific policy area [30]. This is of the greatest importance in the field of transport and there are two types (I and II) of MLG in this field. In Type I, the structure of the MLG is not based on the premise that national governments are the primary political entity and that decision-making takes place within a clustered centralized array (international, domestic, federal, sub-regional, and local) of governments. Although recognizing that the forces of policy between the government layers are now much messier, particularly in Europe's context, the notion that political control is also affected by a changing policy space is focused on multilevel management. In type II, the increase in the numbers of government departments, private-public partnerships, and statutory consultants does not limit the degree to which the central government can influence changes (Table 1) [8,30]. The main reason for discussing these issues in this study is that the interactions between MLG and the transport sector have never been explored. This study also attempts to highlight how transport policy has changed over time, from focusing solely on problem-solving to recognizing that MLG plays a major role in urban transport planning, which is indeed a central part of transport sector. 
Table 1. Types of multi-level governance (MLG) (adapted from [8]).

\begin{tabular}{|c|c|}
\hline Type I & Type II \\
\hline Multi-task jurisdictions & Task-specific jurisdictions \\
\hline $\begin{array}{l}\text { Local authorities responsible for waste, transport, } \\
\text { social services, education }\end{array}$ & $\begin{array}{c}\text { Highways agency responsible for national } \\
\text { trunk roads }\end{array}$ \\
\hline Mutually exclusive jurisdictions at any particular level & Overlapping jurisdictions at all levels \\
\hline Government boundaries do not overlap & $\begin{array}{c}\text { Friends of the Earth can have a national campaign to } \\
\text { counter development at the local airport. }\end{array}$ \\
\hline Limited number of jurisdictions & Unlimited number of jurisdictions \\
\hline Typically, few layers of government & $\begin{array}{l}\text { Issue specific groupings that are geographically } \\
\text { flexible }\end{array}$ \\
\hline Jurisdictions organized in a limited number of levels & No limit to the number of jurisdictional levels \\
\hline E.g., European, national, regional, local & $\begin{array}{l}\text { Informal groupings from local to international and } \\
\text { can be virtual }\end{array}$ \\
\hline Jurisdictions are intended to be permanent & Jurisdictions are intended to be flexible \\
\hline
\end{tabular}

In contrast with Type I institutions, which deal with the government levels responsible for a number of policy areas in line with the 2001 distinction of Hooghe and Marks [31], these tasks-specific agencies are frequently called Type II institutions. The prospect of moving from the socio-technical mobility system to explain the budgetary decisions on public transport and understanding the climate policy within the European context [30] was used to explain this perspective [8].

Another popular, and quite similar, governance perspective is "network governance", which has been extensively applied to issues of public and urban transport. Poku-Boansi et al. (2018) [32] focused on the network of actors involved in decision-making as one of the elements of governance in the introduction of bus rapid transit systems. Legacy et al. (2012) [33] referred to networked governance and strong regulations as a way to overcome the silo mentalities and deliver policy integration for land use and transport. Mu and de Jong (2016) [34] offer the most explicit application of network governance to the same topic, using the case of Urumqi, China. They use the term 'network governance' to describe the more or less stable patterns of relations. da Cruz and Marques (2017) [35] argued that the appropriate way to develop sensible local governance indicators is to use a multi-criteria model that includes a number of objective (quantitative and qualitative) indicators and uses a participatory approach to aggregate them. Based on their study, all indicators and evaluation models are imbued with values, politics and context and should never be overlooked or disguised. Their study concluded that the evaluation model may also be able to further explore the relationship between local governance practices and a number of socio-economic factors by operating with good governance. One of the most interesting aspects of the governance research for policy-makers and practitioners is the application of the above-mentioned concept of purposive governance to the development strategies or concerns where the transport sector plays a significant role. In this view, governance is seen as inseparable from the public good or public values that it seeks to promote or achieve. This approach has been used in several studies on the governance of smart mobility [36], climate change [8] and, to a lesser extent, but still in the same line, the application of the MLG to the discontinuation of the automotive regimes. These studies aimed to analyze what changes in the objectives and the modes of governance would be required to capture an increased public value from the shifts in mobility systems towards a smarter mobility, a more sustainable transport or a less car-based socio-technological regime. Quite similar to Jessop's view on governance as managing complexity and multiple possible scenarios, this perspective considers what opportunities and challenges are available to the state or government, who, despite their diminishing roles and influence, as a key funder or even as a knowledge provider, still retain the task to steer the society towards the socially-agreed development or welfare goals. A good example is given by Mu and de Jong (2016) [34], who developed a cumulative ladder to analyze (network) 
governance deals with the rungs of governance by substantive complexity, strategic uncertainty and institutional deficiency. Finally, a strand in the TG research addresses the biases and shortcomings in the TG research itself [8].

\subsection{What Is Poor Governance in Transport?}

Poor project planning and selection may indicate poor management. Poor project planning and selection generally involves an ineffective investment plan for the sector that selects projects that are not in line with cost-benefit outcomes. Poor planning and selection of projects usually occur if planning processes in the sector do not include a well-designed method for priority investment. It is easier for corrupt officials to influence the planning process and the selection of projects without a method for selecting projects. There are common problems with poor governance and possibly corruption as follows:

- Partialities for new works: Long-term contracts require larger sums of money, thus expanding the resources available to be misappropriated and determined or controlled by (or both) senior officials, enabling them to benefit from bribery (which they would not be able to obtain from lower value contracts). Senior decision-makers, therefore, have incentives to encourage larger contracts, such as new roads, which offer lucrative opportunities for corruption.

- Project selection: Selection of projects may be oriented to those which allow the project participants to draw additional value during the implementation of the projects.

General issues with PG and possibly planning corruption are as follows:

- One alternative project planning is limited: Project planners should consider several alternatives to the project's proposed new approach, including consideration of several modes of transport. The fact that alternatives are not taken into account may simply be logistical but can indicate poor planning.

- No financial assessment carried out: The need for a project or the selected alternative project should be assessed with standard cost-benefit analysis.

\subsection{What Is Good Governance in Transport?}

Government funding for public transport aims, through the public interest of a subsidized transport service, to achieve social and environmental objectives for the residents and tourists. Government is commonly seen as singular (transport authority or state) in the current public transport policies and governance literature. However, countries are not as uniquely or uniformly researched in administrative science as is implied in this document. Different governments operate at a variety of jurisdictions and their actions are generally mutually dependent in a particular policy domain. These different levels of government do not need to co-ordinate policies because differing levels of government lead to differences. This is designed as MLG with recorded public transport problems and practices in urban areas [30].

Governance has been gaining more and more attention from researchers in the recent years. It has been analyzed in relation to a large variety of transport topics, from a modal (maritime, port, urban, inland water, road) or multimodal (transport corridors) perspective and in relation to the overarching development goals (climate change, smart mobility) or policy integration challenges (transport and land use) [21]. In contrast to the diversity of perspectives in the academic research, most policy forums and policy initiatives converge in invoking TG to promote the "good" practices in the elaboration and implementation of transport polices. The recommendations are generally normatively charged, assuming, in most cases, that more transparency, rule of law, equitable, and inclusive policies automatically lead to better and more effective policy decisions. In some cases, indicators are offered to measure the good transport governance [21]. Since roads consist of complex interdependent long-lasting networks and resources. Including many parties, responsive and clear strategies, plans, and projects are important if the industry is to operate well. Providing stakeholders 
with the opportunity to participate in drawing up plans to explain the directions of its sector toward providing a rationale for good planning, would encourage efficiency and responsibility. Good selection of projects is consistent with plans and clearly justifies the implementation and contributes once again to accountability and performance [37].

\subsection{How Governance in Transport Can Affect Climate Change?}

Local governance may have an important impact on the threat to environment. Municipal governments are responsible for quality decision-making and infrastructure delivery and urban planning (i.e., avoiding or not protecting new developments in dangerous areas allowing buffer zones). The previous studies on urban governance and poor development show that demand and supply constraints exist to achieve PG $[30,38]$. These can be applied effectively to adaptation and urban environmental management issues related to governance. On the supply side, a number of factors limit municipal governments [38]. Governance has a positive impact on climate change's environmental performance. Promoting GG can help to create a cleaner environment.

The effect of mismanagement in corporate activities that are vulnerable to conflicts of interest, such as sales of a product, major acquisitions or strategic opportunities would result in a material corporate event, especially if not voted by shareholders. Such events, while company-specific, can collectively affect returns within a portfolio. A board of directors owes the shareholders a fiduciary responsibility to ensure GG, but its efforts may be short [39]. MLG was effective as a climate-change policy system within a European context but to date, better public transport policy was not used to identify, clarify, and promote given the cross-national impacts of public transport policies. MLG theory's main premise is that domestic government is not inherently a dominant policy unit and in the sense of continuous negotiations between nesting governments in different territorial areas [30].

For the sub-samples of high- to-middle-and-low-income countries, the impact of governance is negligible. Strong environmental protection policies exist in high-income countries, although their relatively weak environmental policies must be improved by others in order to reinforce developing countries' environmental institutions. Researchers proposed four simplified hypotheses of the environmental effects of governance and institutional quality including: (i) the effect of government size; (ii) the effect of efficiency; (iii) the effect of commercial regulation; and (iv) the effect of stability [7]. Given so far incomplete progress, new technology, strict policies, and behavior change can result in the transition to reducing GHG emissions. Key development items in the transport sector adopted by Intergovernmental Panel on Climate Change [40] include:

- Continued increase in the average annual per capita passenger $\mathrm{km}$, but indicating that ownership and use of LDVs in some OECD countries may have peaked;

- Operation of particulate matter and black carbon reduction technologies, especially in OECD countries;

- Increased use of aviation and renewable biofuels;

- Increased access to the infrastructure of choice in developing countries;

- Increased carbon intensity of freight logistics companies' activities, slow steaming of ships, and the shipping industry's demand for GHG emissions;

- Increased understanding that urban planning and the design of pedestrian, bike, bus, and light rail networks can have an impact on policy choices, while addressing wider sustainability issues, such as health, accessibility and security;

- Effective comparative cost analysis for passengers and freight between modes; and

- Growing policies that slow LDV growth, particularly in Asia, including investment in non-motorized transport systems.

\subsection{Role of Government Institutions and Participation of Stakeholders in the Governance Process}

From an institutional point of view, governance systems can be categorized into formal, informal, or the combination of the two. Laws and regulations are some examples of formal systems, and elder 
councils, social networks, patronage, and so on, can be considered as informal systems [41]. However, it is worth mentioning that the majority of people in the world do not have access to formal administration systems, and they live in regions with customary institutions [42]. In order to achieve some kind of rights over the governance, policy-makers have tried to improve institutional arrangements through the participation of stakeholders [43]. It is worth mentioning that the typology of governance is primarily concerned with managing the development of land use through collaboration with various stakeholders. It is not only about government-private collaboration, but also the cooperation of multi-level stakeholders. Many local, national, regional, and international organizations have made substantial efforts to meet the challenge of rapid urbanization [44]. In general, stakeholders recognize the role of governance actors in the implementation process, with advisory boards playing a key role, as well as regulators and governance experts (often included in the network or the specific monitoring body). In this context, the empiric results of Rodríguez-Pose et al.'s (2014) [45] study have shown that the regions in which governance gaps are more severe and the legal and government structures are more deficient are likely to be those most in need of institutional reform in EU's regions.

The stakeholders' participation in transnational cooperation networks, where regional policy-makers can benefit from each other's experience and practice, the establishment of regional administration programs to provide advice on governance techniques could be very beneficial [46]. The role of government institutions at this stage is to provide adequate incentives for the development of effective collaborations between all stakeholders in the governance system, i.e., to set the conditions for an "inclusive" approach to the identification of policy priorities. The risk, however, is that vested interests of the most powerful regional stakeholders and lobbies may condition decision-makers, allow partisan politics to prevail [47].

Table 2 provides a brief overview of the journal-articles focusing on transport policy and governance in recent years. For each article, it identifies the specific subject (the transport sub-sector), the role of government institutions and their position in the governance concept. The period extends over eight years (2010-2018) and focuses on academic research where the term "governance" has been used in the title and/or body of the article.

Table 2. The linkage between government institution and transport governance strategies.

\begin{tabular}{|c|c|c|c|}
\hline Transport Governance Strategies & Government Institution & Topic & References \\
\hline $\begin{array}{l}\text { To investigate the prospect of deep } \\
\text { reductions in } \mathrm{CO}_{2} \text { emissions from transport } \\
\text { by examining the key policy levers for } \\
\text { change and taking into account the } \\
\text { governance issues surrounding them. }\end{array}$ & $\begin{array}{c}\text { Use of multi-level governance as a conceptual } \\
\text { approach to study policy development, } \\
\text { implementation, efficiency and accountability. } \\
\text { Application of the multi-level governance analytical } \\
\text { model and its forms to the dynamic policy objectives } \\
\text { that go beyond geographical, administrative and } \\
\text { national/supranational context and } \\
\text { intervention demands. }\end{array}$ & $\begin{array}{c}\text { Climate change and } \\
\text { transport }\end{array}$ & $\begin{array}{l}\text { Marsden and Rye } \\
\text { (2010) [8] }\end{array}$ \\
\hline $\begin{array}{l}\text { To analyze the maritime policy system and } \\
\text { how problems of mobility, movement, } \\
\text { transition and the growing pace of these } \\
\text { changes can be addressed in a new } \\
\text { governance context. }\end{array}$ & $\begin{array}{l}\text { Overall framework and relationships on maritime } \\
\text { governance. The focus is on the failure of maritime } \\
\text { governance due to the insufficiency of its current } \\
\text { form to the sector's needs and characteristics. }\end{array}$ & $\begin{array}{l}\text { Maritime } \\
\text { transport }\end{array}$ & Roe (2013) [48] \\
\hline $\begin{array}{l}\text { To analyze the differences between the two } \\
\text { governance modes applied to the Yangtze } \\
\text { River and the Pearl River arteries and to } \\
\text { explore their various impacts on waterway } \\
\text { system development. }\end{array}$ & $\begin{array}{l}\text { Governance modes seen as either a Y-mode (central } \\
\text { government responsible for overseeing the market } \\
\text { for inland water transportation) or a P-mode (central } \\
\text { government as largely a coordinator with } \\
\text { river-managed local governments). }\end{array}$ & $\begin{array}{l}\text { Inland } \\
\text { water } \\
\text { transport }\end{array}$ & Jiang et al. (2015) [49] \\
\hline $\begin{array}{l}\text { The focus is on power decentralization, i.e., } \\
\text { the gradual shift from highly centralized } \\
\text { ownership and decision-making to a port } \\
\text { governance landscape that provides more } \\
\text { room for corporatization and participation } \\
\text { in the private sector. }\end{array}$ & $\begin{array}{l}\text { In response to changes in the global and domestic } \\
\text { economic context, changes in China's government } \\
\text { reform and broader public policies have been } \\
\text { investigated by analyzing the evolution of port } \\
\text { governance in China. }\end{array}$ & Ports & $\begin{array}{l}\text { Notteboom and Yang } \\
\text { (2017) [50] }\end{array}$ \\
\hline $\begin{array}{l}\text { The focus was on analyzing the context of } \\
\text { literature on multi-level governance and its } \\
\text { application to public transport by } \\
\text { examining case studies. }\end{array}$ & $\begin{array}{l}\text { Application of the principle of multi-level } \\
\text { governance, i.e., the idea is that the national level of } \\
\text { government is not inherently the dominant policy } \\
\text { making entity and more typically takes place. } \\
\text { Multi-level governance depends on the situation, } \\
\text { policy formulation, and execution within a } \\
\text { framework of continuous negotiation between } \\
\text { nested governments at several regional levels. }\end{array}$ & Public transport & $\begin{array}{l}\text { Veeneman and } \\
\text { Mulley (2018) [51] }\end{array}$ \\
\hline
\end{tabular}




\section{Transport and Climate Change: Where Is the Problem?}

The transport sector's contribution to the climate change problem goes beyond one point and is heavily affected by the activities of formal agencies, individuals. and organizations [8]. There is a direct effect of transport on the planet where there is typically a simple and well-established correlation between cause and effect. For example, noise and carbon monoxide emissions are known to have direct harmful effects. The indirect impact on ecological processes of transport activities include the immediate effect of transport on the world where there is generally a clear and well-established relationship between cause and effect [51]. The various, frequently unpredicted consequences of direct and indirect impacts on an environment were taken into account. Climate change is the cumulative impact of several natural and anthropogenic influences with diverse causes and consequences in which transport plays an important role. There are environmental concerns in the transport sector [51]. Greenhouse gas emissions, new technology, and action plans for the mitigation of the effects of climate change are being analyzed to evaluate the role of transport systems, including land, air, and water [52].

Adaptation measures are slowly emerging in different levels of governance throughout Europe to meet these challenges. Politicians are under pressure to address climate change and approach sustainable transport through the promotion of sustainable practice and behavioral change $[53,54]$. In addition to improving vehicle fuel economy and reducing carbon content from power sources, the transport sector also needs to develop new design frameworks [55].

When economies grow, a vital element of economic development, human welfare, and transport activity rises around the world. For most politicians, traffic deaths and injuries, congestion, air pollution, and dependence on oil are the most pressing problems linked to this increased transport activity. These issues are particularly acute in the developing world's fastest growing economies. It is possible to mitigate greenhouse gas (GHG) emissions by highlighting synergies and co-benefits, as well as other transport priorities. The transport industry plays a key and growing role in the global use of energy and GHG emissions. Transport energy consumption in 2004 amounted to $26 \%$ of the world's energy consumption and transport accounted for about $23 \%$ of global GHG emissions $[51,55]$. Energy use rose the most in the transport sector of all end-use industries from 1990 to 2002. For 77 EJ5 (the global primary energy production in 2004 was 446 quads, equivalent to $471 \mathrm{EJ}$ ) of the total energy consumption in transport, more than three-quarters are road vehicles, with light and freight trucks owning the lion's share [56]. Automobile hegemony contributes to unsustainable outcomes, including its contribution to climate change. An ideal path to sustainable transport is unlikely to be accomplished in a laissez-faire policy setting and is unlikely to be solved by any single solution. Rather, carefully crafted initiatives that match well with specific national circumstances and operate in an integrated way to achieve meaningful change throughout the transport system are likely to be needed $[57,58]$.

Recognized problems in all international platforms are a continually changing climate and global warming. One of the main reasons for global warming is greenhouse gas emissions caused mainly by the use of personal cars as transport. In all global forums, a continually changing environment and global warming are recognized issues. Consumer behavior in the purchasing and use of personal cars, however, involves a diverse set of decisions based on the expectations of product needs, social factors, beliefs, standards, and efforts to promote environmentally friendly behavior [2].

\subsection{Transport and Air Pollution}

A key component of well-being and development is openness in modern societies. For the purpose of economic life as well as life quality, it is important for individuals, families, and businessmen to exchange and communicate with people and services where operations are held [3]. Transport may contribute to urban degradation and loss of quality of life and economic productivity as a result of delays, or frustration due to congestion and stress. Transport involves fossil fuels combustion to produce moving energy [59]. Pollution is caused by incomplete carbon reactions, unburned hydrocarbons or other components found in electric vehicle or gasoline oil [60] or water during combustion [51]. The amount of pollution in these cities can be expected to correspond with these 
proportions in general (but not exactly), although the relative costs of transport harm may have no effect on these proportions. Transport activity has a number of impacts including congestion [48], air pollution [51] nitrogen oxide emissions $\left(\mathrm{NO}_{2}\right)$, and carbon monoxide (CO) emissions [59] and black smoke. Transport development is also counterproductive to the economy's efficient functioning (through road congestion). Human exposure to this waste causes adverse health effects when driving, biking, or actually staying at home [59].

\subsection{Transport and Greenhouse Effect: Carbon Emissions Management}

Although the timing and impact of climate change remains uncertain, the risks of significant adverse effects are already evident. The stabilization of atmospheric concentrations of greenhouse gases will require a dramatic reduction in annual emissions to a small proportion of the current levels [61]. Climate change has become a global environmental issue. Greenhouse gas emissions bring a long-term change to the whole climate system. The most important anthropogenic gas affecting the climate is carbon dioxide. Transport accounted for $23 \%$ of global GHG emissions in 2009 compared to $41 \%$ for energy. Transport is however expected to become the largest emitter of GHGs by 2035, accounting for $46 \%$ of global emissions, and by 2050 the largest growing source of $\mathrm{CO}_{2}$ emissions are expected to be transport, emitting $80 \%$. Asia accounted for $19 \%$ of the total $\mathrm{CO}_{2}$ emissions associated with the worldwide transport sector in 2006. By 2030, Asia's share of total global transport-related $\mathrm{CO}_{2}$ emissions will rise to $31 \%$ [51].

Transport accounts for $26 \%$ of greenhouse gas (GHG) emissions [52] about two-thirds of which originate in the wealthier $10 \%$ of countries [62]. The impacts on emissions from greenhouse gases, as well as emission mitigation and adjustment measures, can vary greatly depending on the particular transport mode which can also be classified as travel modes (land, air and water). With regard to transport, the three transport subsectors-passenger transport, freight and information-have different requirements for transport systems [63]. However, land-based transport systems are generally the most widely used in urban areas and can be split into traffic and road-based systems that are recognized as the major contributors to transport greenhouse gas emissions [52]. The OECD (2009) [64] states that road transport accounted for $84 \%$ of the $\mathrm{CO}_{2}$ emission of the transport industry and $21 \%$ of global $\mathrm{CO}_{2}$ emissions from energy. Oil is the predominant transport fuel source, representing $81 \%$ of the transport sector's total energy use. This dependency on fossil fuels is one of the few industry sectors where emissions are still increasing in terms of transport contributing to greenhouse gasses [52]. Figure 1 presents analytical tools and metrics for quantifying the extent of climate change impacts (i.e., agriculture and forestry, ecosystems, energy production and consumption, social effects) due to a variety of source emissions (e.g., $\mathrm{CO}_{2}, \mathrm{CH}_{4}, \mathrm{~N}_{2} \mathrm{O}, \mathrm{HFC}, \mathrm{PFC}, \mathrm{NO}_{x}, \mathrm{SO}_{2}$ ). The metric should be simple to understand and scientifically sound, enabling a comparison of the differences in emissions and providing guidance on decisions on our future moves. When choosing a metric, it is important that it is closely linked to the impact of the concern (i.e., if climate stabilization is of our concern about a given temperature change, then the chosen metric should provide information on temperature change). Unfortunately, the impacts of and inherently damaging measures that are increasingly relevant to climate change are increasing insecurity (Figure 1).

\subsection{Green Modes in Transport}

Green transport involves walking, cycling, regular public transit, and travel by rail [65]. Green transport vehicles include a range of vehicles with low emissions, including dual-energy vehicles, natural gas vehicles, electric vehicles, and hydrogen and solar vehicles. Green transport also includes various electric vehicles, like trolley buses, trams, light rail, and subways. Green transport is a new concept and practice objective, which specifically refers to the convenient, safe, effective and pollutant urban transit system. Green transport adapts to the developments in the growth of the natural system, which is led by public transport and integrates with the climate and urban development [66]. The concept of green transport is proposed as well as the concept of sustainable development, which is 
the passage from 'vehicle-oriented' to person-orientated. Green transport is committed to reducing the use of vehicles for private vehicles, increasing the use of public transport, walking, cycling, and smooth energy use [67]. Building a green transport system is good for intensive use of road resources to facilitate traffic congestion, reduce energy consumption to conserve energy, reduce emissions to improve air quality, reduce carbon emissions to reduce the greenhouse effect and build residential towns to improve the health of citizens. Green travel, with flexibility and high timeliness, has a good foundation for development in China.

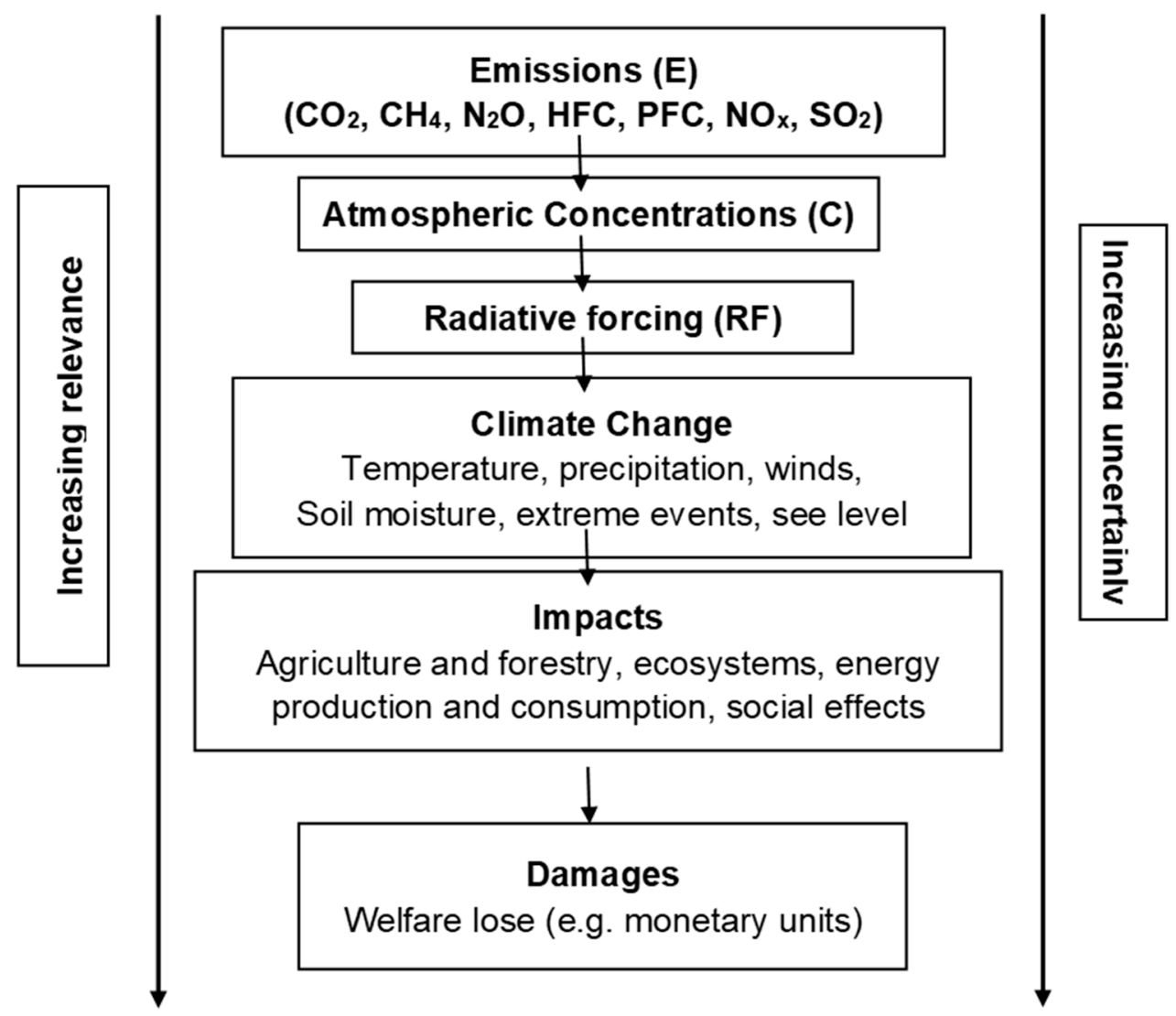

Figure 1. Cause and effect chain of the potential climate effect of emissions.

\subsection{Maritime Transport and Climate Change}

A large part of the problem of global climate change is the shipping industry's responsibility. Ocean-going vessels can account for more than $3 \%$ of global carbon dioxide emissions $[51,68]$. The report begins by quantifying the scale of the challenge faced by climate change, considers the role of shipping in terms of mitigation, and presents and evaluates a range of distribution methods for estimating international shipping $\mathrm{CO}_{2}$ emissions at national level [56]. This is similar to large countries that emit carbon, and the industry is growing rapidly. It would indeed be the sixth largest producer of greenhouse gas emissions if global shipping were a country. The only countries that emit more carbon dioxide than the world's transport fleets are the USA, China, Russia, India, and Japan. However, carbon dioxide emissions from sea vessels are not regulated at the moment [68]. The industry is exploring ways of reducing greenhouse gas emissions through the activities of the International Maritime Organization (IMO). The IMO has developed a global action plan on the reduction of international emissions of GHGs from shipping and is now working towards a sound system to regulate shipping globally [51]. 


\subsection{Air Transport (Aviation) and Climate Change}

Figure 2 illustrates the projected use of energy by means of transport (e.g., water, air, rail, freight, bus, wheeler) and this evolution is based on the evolution of the population. As shown in Figure 2, the LDVs (mostly private vehicles) are the most energy-consuming sector, which is followed by freight and air transport. The projections underlying these curves assume that global oil supplies will be capable of meeting the growing demand for transported petroleum-based fuels. This figure attempts to show that the global economy will continue to grow by 2050 [51]. While the technologies used in motor vehicles continue to improve the efficiency of greenhouse gas emissions, the increasing weight and power of vehicles that comprise the global fleet compensates these increases in efficiency.

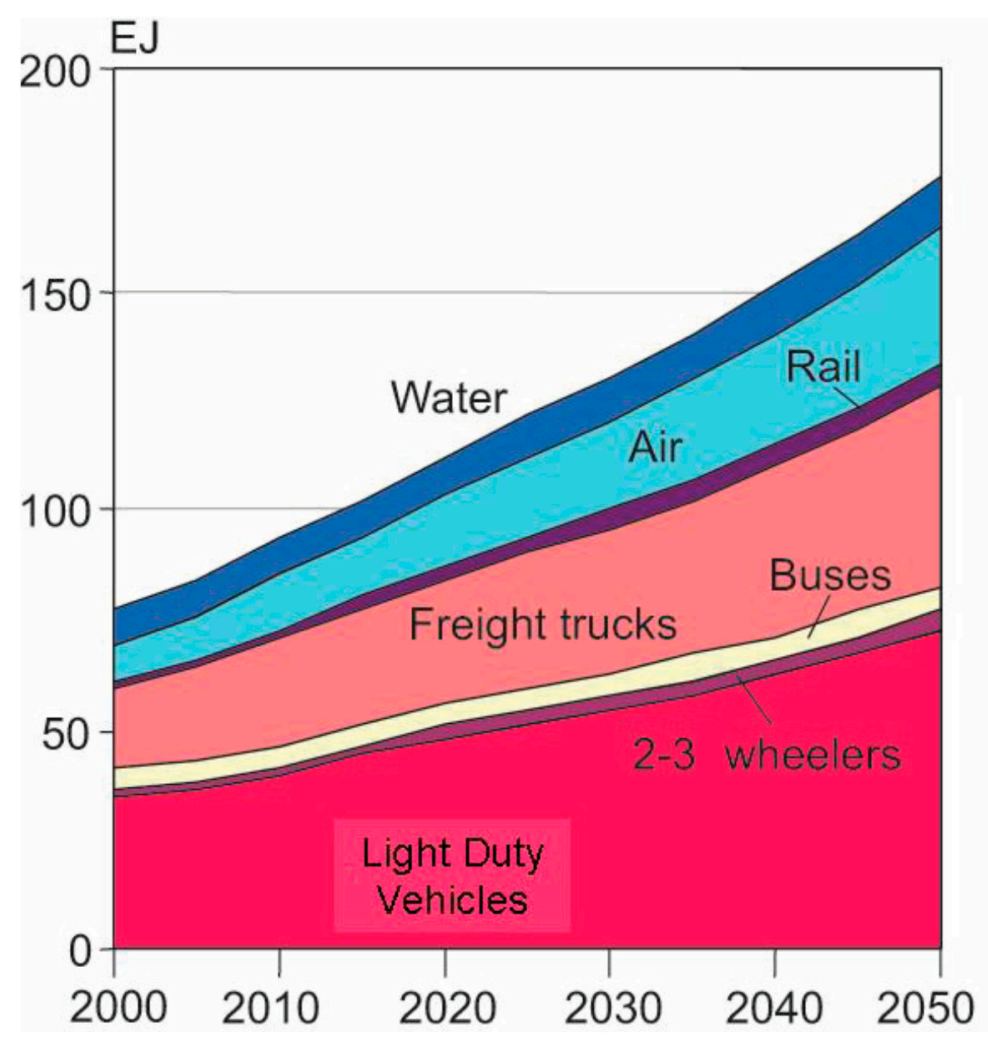

Figure 2. Projected energy usage by transport sector. Source: [53].

The radiative balance of atmosphere and hence the climate system is affected by the emissions from aircraft motors through several mechanisms. These include carbon dioxide, $\mathrm{CO}_{2}$ and nitrogen oxide emissions, $\mathrm{NO}_{2}$ emissions, which have an impact on atmosphere chemistry and are responsible for changes to the abundance of ozone $\left(\mathrm{O}_{3}\right)$ and methane $\left(\mathrm{CH}_{4}\right)$. The climate effect of airborne or directly emitted water vapor is assumed to be negligible. Fuel sulfur is converted into $\mathrm{H}_{2} \mathrm{SO}_{4}$ gaseous-an important precursor of atmospheric aerosol. In air transport, the microphysical characteristics of clouds, hence the optical properties of air pollution, can disperse and absorb the incoming solar radiation directly and indirectly [69].

With fuel costs of about $20 \%$ of the total cost, efforts are made to minimize the fuel consumption per passenger mile flown. Air transport is extremely competitive. The airline operator's perspective is that more efficient engines are part of the long-term solution and creativity in this area. Improved short-term weather forecasts, together with better air traffic management, often offer opportunities to reduce fuel consumption $[51,55,57]$. There are a number of areas where the benefits can flow. Improved destination terminal forecasts result in less fuel being transported. Everything being equal, a lighter aircraft burns less fuel than a heavier aircraft [51]. Strengthened en route wind forecasts provide an opportunity for the airline to maximize its tailwind components by selecting track and flight level. 
Improved air traffic management can reduce aircraft taxiing and retention times. As airliners cross from jet engines in high vapor, they freeze in the troposphere. Since ice crystals are long-term efficient radiation absorbers, they have a higher greenhouse effect than the carbon dioxide gas produced by jet engines. Though, $\mathrm{CO}_{2}$ can last from 75 to 100 years [51].

\section{Toward Effective Transport for Better Climate Mitigation}

Transport is undoubtedly an imperative catalyst for activating and stimulating the beat of economic, social, political, and strategic advancement of any society. To accomplish this, transport infrastructures must be soundly developed to guarantee the movement of people and goods rapidly, economically, securely, easily, and in an environmental-friendly way [70]. Transport policies can be defined as standards, principles, and rules formulated or adopted by a government to accomplish its long-term goals of efficient public transport system. The transport policies also serve as regulatory framework which guides all activities in the transport sector. The need to develop a transport policy that is responsible to the needs of the country and its people is essential for any country [71]. Transport policy, therefore, provides guidance on the planning, development, coordination, management, monitoring, and regulations of the transport sector with its basic purpose of developing a suitable, secure and sustainable integrated transport system, which is efficient and affordable in a progressive and competitive market environment [72].

Transport policy is conducted within a complex framework of different jurisdictions, different objectives and significant interactions with other sectors and different aspects of economic and social life. TG, in line with the general governance debate, has received increasing attention from scholars in numerous disciplines and with respect to many, if not all, segments of the transport activities. TG is often evoked in the context of the increasing complexity of general transport decision-making processes due to a number of recent and interrelated developments, such as the increased role of non-state actors and/or declining power of the state [30], climate change [8], rapid technological developments and uncertainties, and related changes of the socio-technological regime and rise of supranational actors, such as the European Union [36]. In addition to understanding the responsibility at various levels of government, there is the notion that different levels of government retain or use different policy levers and, crucially, have different perspectives.

MLG has demonstrated its usefulness as a framework to analyze the implementation of climate change policies. It seems that it is increasingly difficult and artificial to maintain a discrete hierarchy of decisions, led by Type I institutions, because of travel and the spatial distribution of businesses [8]. The fact that intelligent transport systems and the environment have an impact relationship is a major economic and social cost by contributing to reducing the negative impact of congestion in transport infrastructure. It should also distance itself from the urban plan that promotes site regeneration [4]. For example, about $86 \%$ of shipping comes from diesel engines with a lifetime of $30-40$ years, thus reducing comparatively the level of greater engine efficiencies. Many new technologies can be useful for better climate control transport. For example, about $86 \%$ of shipping comes from diesel engines with a lifespan of 30-40 years, thus reducing the level of higher engine efficiencies in comparison. Several new technologies can be useful for the better transport of climate control [51].

Shipping companies have many ways to reduce global warming pollutant emissions at their disposal. They include reducing emissions but also saving ship operators' fuel and, thus, money; switching to cleaner fuels; and implementing technical and operational measures to improve fuel efficiency. Some of these solutions, such as speed reduction and weather routing, can be used quickly, easily and in certain cases with financial benefits for shippers [67]. The policies for improving the efficiency face some barrier where the first three barriers are market imperfections and the last one is just a characteristic of transport technology and markets [7]. 


\section{Discussion}

The transport sector plays a vital role in the development of countries as economic activity drives the market for transport, meeting both the needs of freight and passenger transport. Climate change governance poses great challenges to current political and bureaucratic structures. Transport systems have evolved to address other issues and now need to be tailored to address the emerging challenges of climate change. Overall, there is a lack of information on climate change mitigation and adaptation among transport agencies due to good/weak governance in the transport sector [53].

Most efforts related to transport and climate change focused on mitigating and reducing transport's contribution to climate change [73]. Although mitigating practices are essential to lessen the climate change threat, adaptive efforts to create resilience and protect against effects should be rapidly developed [74]. In recent trends in land-based transport systems, new solutions need to address the challenges of climate change, sustainable development, mobility, and the livelihood of cities. This requires strong and sustained national, regional and local governments and a renewal of policy incentive for change, as environmental impacts place the issue of transport at the top of the international policy agenda. Preparing for climate change impacts would involve a government-wide approach to adaptation planning, involving all levels from national to local based on available resources and capability, and encouraging private industry and individuals to accelerate the adaptation process [75]. However, adaptive capacity building efforts are needed to begin with encouraging supporting governance, supporting social structures, and providing information through ongoing research, data collection, and monitoring. After an adaptive capacity has been achieved by a society, adaptation measures can be implemented [53]. In addition to improving the fuel economy of vehicles and reducing carbon content in energy sources, the transport sector needs to develop new planning frameworks, evaluating, in particular, the role that national governments could play in setting up institutions, policies, plans, and actions for climate change mitigation and adaptation.

In a more general way, a large part of the TG work stems from the extensive previous research on the role of institutions in the evolution of transport systems, which is an established area of the transport research. There are numerous studies on the extent to which institutional settings affect the implementation of policies. The institutional arrangements at the city level, i.e., differences in the distribution of responsibilities within the governmental sector and between the public and the private sector, have a direct impact on the effective implementation of the policy objectives or, at least, of some policy instruments, such as transport investments [76]. In fact, governmental and non-governmental policies and resources can support climate change adaptation actions locally and nationally. This clears the urgent need for MLG in the transport sector in order to perceive the nature and structure of governing networks and their inter-relationship with issues like institutional arrangements, behavioral change, control, capacity, accountability, and efficiency in the transport system. Whilst it depends on the area of problem, the overall obstacles to adaptation and mitigation to climate change are the overall lack of knowledge on the need to adapt climate change infrastructure to the impacts and the adjustment methods to apply [27].

Marsden and Rye (2010) [8] reviewed the background and case for analyzing the governance of carbon emissions management within transport. They concluded that the distribution of responsibilities between spatial levels is not yet clear and consequently, there is a considerable lack of commitment to demand management and transport strategies in order to contribute to carbon reduction. The MLG has been appreciated as a useful framework through which the policy-making process in a wide variety of sectors (economic policy, regional policy, environmental policy, etc.) can be solved while also greater accuracy in relation to conceptual arguments around democratic accountability and legitimacy could be provided [8]. The transport sector, in general, and planned adaptation measures in climate change, in particular, have not been evaluated yet across the analytical lens of the MLG. The countries have been recognized active in the field of adaptation [72] which is important in further surveying the extent to which the MLG in the transport system contribute [8]. This would lead to more practical 
and realistic adaptation strategies in the future, resulting in innovation and divergence of transport policy approaches.

Governance and policy have a direct impact on transport activities. As a result, infrastructure and urban planning policies can make significant contributions to mitigating the transport system. Policy measures that impose physical constraints and pricing schemes could encourage a modal shift from LDVs to other surface transport modes. LDV parking management, for example, is a simple form of cost-effective pricing tool [77]. Pricing schemes that manage and organize transport demand (such as congestion charges), can have a major impact on modal shifts as well as on other key local issues as follows: (1) A reduction in car traffic to and from the congestion area (e.g., both London and Stockholm have experienced a significant decrease in car traffic leading to improved travel time reliability); (2) contribute to a better balanced modal split (i.e., due to investments in transport infrastructure along with the revenues collected through the scheme, other modes of transport are becoming more popular, enabling a more balanced modal split to be achieved); (3) encourage the use/purchase of cleaner vehicles (i.e., due to a fair system of exemptions, the proportion of clean vehicles passing the control is increasing); and (4) lower emissions and cleaner air (i.e., the reduction in traffic within a defined zone lead to a clear fall in emissions from road traffic $\left(\mathrm{NO}_{X}, \mathrm{CO}_{2}\right.$, and PM) [77].

With the negative impacts of transport activities, decision-makers are becoming increasingly aware of the need to adopt solutions that facilitate pricing schemes and sustainable transport systems. Therefore, in the decision-making and policy-making process, the development of indicators for measuring and evaluating transport activities can play an important role. As suggested by Litman (2007) [78], transport-related metrics should be balanced, representing a combination of economic, social, and environmental priorities and can be implemented at various levels as follows:

- Planning process-evaluating planning and investment practices

- Options and incentives-examining consumer options and markets.

- Travel behavior-evaluating vehicle ownership, vehicle travel, split mode, etc.

- Physical impacts—assessing pollution emissions and crash rates, land use, etc.

- Effects on humans and the environment-measuring mortality, morbidity, environmental degradation, etc.

- Economic effects-providing monetized economic cost estimates, reduced productivity, property values, etc.

- Performance targets-determining the degree to which the desired standards and objectives are achieved.

Dedicated bus routes, possibly in combination with vehicle access charges for LDVs, can be powerful tools for quick transfers to public transport. Policies that promote the incorporation of moderate to high-density urban property development with transit-oriented design approaches which incorporate housing, jobs, and retail services may attract pedestrians and cyclists, while providing the dual benefits of decreasing vehicle reliance and avoiding urban sprawl. Sparing GHG emissions can lead to health, productivity, and social opportunities if the use of polygendered urban design and comprehensive smart growth policies could reduce LDV travels. Policies to promote the construction of more roads, airports, and other infrastructure can contribute to short-term congestion but can also trigger demand for travel and building-based GHG emissions.

\section{Conclusions}

As the third largest contributor to human-made greenhouse gas emissions, transport will have to find ways to reduce emissions. This knowledge should be science-based, established with close contact with users, and consistent throughout the timeframe provided by users. The ultimate goal of this review study is to provide policymakers with realistic knowledge and understanding of how to develop different modes of TG at different levels that can put an end to practical climate change interventions. Based on the findings of this study, if developing nations are to achieve their 
economic transformation, they should manage their public transport effectively to replace future LDV consumption. They require a functional, reliable, and efficient transport systems, and can only be derived from properly formulated and implemented policies with the assistance of all relevant private, academic, and government agencies working together [79,80].

Overall, transport policy and governance must be reviewed to take account of the concerns of climate change and natural disasters. However, there is a lack of information among transport agencies with regard to climate change mitigation and adaptation resulted from good/weak governance system in the transport sector. Since transport infrastructure requires substantial investment in both construction and maintenance and in order to cope with changing climatic conditions, priority should be given to increasing initial investment. Climate change is a complex policy issue spanning all territorial governmental levels. Transport is a particularly challenging policy sector because it does not respect administrative boundaries and, therefore, responsibility for initiative is also challenged across administrative borders. Based on the findings, MLG has proved to be a useful analysis framework to start studying the implementation of climate change policies. It appears that, due to the nature of travel and the spatial distribution of businesses, it is becoming increasingly difficult and artificial to preserve a discreet level of hierarchical decision-making. In this context, the life cycle cost of roads should be fully assessed in order to gain better insight into the initial investment required and the later stage operation and maintenance costs. Investment costs should be calculated by taking into account the cost of the risks associated with expected road traffic and climate change.

This study revealed that developing nations need to manage their pricing methods in the transport system and use that to promote transport systems that are unlikely to affect the climate.

A national-to-local adaptation plan approach will be required to be prepared for climate change effects, which involves all levels of capacity and resources and empowers private sector and individuals to facilitate the process of adaptation.

The following collection of guidelines and general strategies is needed to make it easier to adapt transport to the impacts of climate change:

- The transport community is needed to be informed about the importance of tackling the climate change;

- Leadership at the top level is needed to provide policy clarity;

- Partnerships focused on climate change should be developed at all levels of governance and include the private sector;

- Increased support and guidance are needed to build institutional capacity to address climate change; and

- Synergies should be established between priorities and projects undertaken at all levels of government and the private sector.

In essence, the following recommendations should be considered by policy-makers:

1. Planning and design of infrastructure to address climate potential risks;

2. Attempting to engage the community broadly and involving professionals from a wide range of disciplines, including geology, hydrology, engineering, statistics, ecology, biology, economics, and financial management;

3. Constantly updating impact assessments and cost and benefit analyzes of adaptive strategies;

4. Emphasizing necessity ongoing research and development on climate change and variability; and

5. Improving emergency management and resiliency plans for extreme events identified by current science.

Indeed, indicators and dimensions will vary from country to country, reflecting specific circumstances that characterize the local government and transport community setting of each country. In addition, mitigation and adaptation strategies will vary depending on the composition of the decision-making group, which we consider to be a shortcoming of this study. It is, therefore, 
essential to assess the function of a heterogeneous decision-making group as their role is crucial to the credibility, robustness, and acceptability of a multi-criteria transparency index for transport systems with minimal climate impact. Therefore, future studies should explore the determinants of the variation in transparency levels across municipalities decision-making groups and highlight the role of the stakeholders involved, particularly local officials and the general public.

Author Contributions: Conceptualization, S.Z. and F.W.; methodology, S.Z.; validation, F.W.; formal analysis, S.Z.; writing — original draft preparation, S.Z.; writing—review and editing, F.W.; funding acquisition, S.Z. All authors have read and agreed to the published version of the manuscript.

Funding: This research was funded by the National Natural Science Foundation of China, grant number 41701120. Frank Witlox acknowledges funding received from Eesti Teadusagentuur [PUT PRG306].

Conflicts of Interest: The authors declare no conflict of interest. The funders had no role in the design of the study; in the collection, analyses, or interpretation of data; in the writing of the manuscript, or in the decision to publish the results.

\section{References}

1. Laphong, J.K.; Dihingia, H.; Borah, S. Advanced road traffic management system. IJISSET 2019, 4, 168-169.

2. Saleem, M.A.; Eagle, L.; Low, D. Climate change behaviors related to purchase and use of personal cars: Development and validation of eco-socially conscious consumer behavior scale. Transp. Res. Part D 2018, 59, 65-85. [CrossRef]

3. Van Acker, V.; Goodwin, P.; Witlox, F. Key research themes on travel behavior, lifestyle, and sustainable urban mobility. Int. J. Sustain. Transp. 2016, 10, 25-32. [CrossRef]

4. De Vos, J.; Schwanen, T.; Van Acker, V.; Witlox, F. Travel and subjective well-being: A focus on findings, methods and future research needs. Transp. Rev. 2013, 33, 421-442. [CrossRef]

5. Stjernborg, V.; Mattisson, O. The role of public transport in society-A case study of general policy documents in Sweden. Sustainability 2016, 8, 1120. [CrossRef]

6. Pew Center on Global Climate Change. Climate Change 101: Adaptation. Article from Series Climate Change 101: Understanding and Responding to Global Climate Change. Available online: http://www. pewclimate.org/docUploads/Adaptation_0.pdf2009 (accessed on 10 August 2019).

7. Arfin, T.; Aquatar, M.O.; Waghmare, S.S. Mitigation Strategies to Greenhouse Gas Emission Control: A Database for Emission Factors. IJSRD 2015, 3, 908-917.

8. Marsden, G.; Rye, T. The governance of transport and climate change. J. Transp. Geogr. 2010, 18, 669-678. [CrossRef]

9. Mittal, P.K.; Gottam, G.S.; Gupta, B.; Bilochi, D.R. The effect of climate change on productivity and reproductive and health performance of livestock: A review. J. Entomol. 2019, 7, 4-9.

10. Afenyo, M.; Jiang, C.; Ng, A.K.Y. Climate change and Arctic shipping: A method for assessing the impacts of oil spills in the Arctic. Transp. Res. Part D 2019. [CrossRef]

11. Schweikert, A.; Chinowsky, P.; Espinet, X.; Tarbert, M. Climate change and infrastructure impacts: Comparing the impact on roads in ten countries through 2100. Procedia Eng. 2014, 78, 306-316. [CrossRef]

12. Saboohi, R.; Barani, H.; Khodagholi, M.; Abedi Sarvestani, A.; Tahmasebi, A. Nomads' Indigenous Knowledge and Their Adaptation to Climate changes in Semirom City in Central Iran. Theor. Appl. Climatol. 2019, 137, 1377-1384. [CrossRef]

13. Nath, P.; Behera, B. Critical review of impact of and adaptation to climate change in developed and developing economies. Environ. Dev. Sustain. 2011, 13, 141-162. [CrossRef]

14. Márquez, A.L.; Real, R.; Olivero, J.; Estrada, A. Ombining climate with other influential factors for modelling the impact of climate change on species distribution. Clim. Chang. 2011, 108, 135-157. [CrossRef]

15. Da Cruz, N.F.; Marques, R.C. Scorecards for sustainable local governments. Cities 2014, 39, 165-170. [CrossRef]

16. Abas, M.A. Public Policy and Governance: Theory and Practice. Available online: https://www.researchgate. net/profile/Muhamad_Azahar_Abas/publication/332406879_Public_Policy_and_Governance_Theory_ and_Practice/links/5cb29fbe4585156cd7964bfa/Public-Policy-and-Governance-Theory-and-Practice.pdf (accessed on 12 July 2019).

17. Katsamunska, P. The concept of governance and public governance theories. Econ. Altern. 2016, 2, $133-141$. 
18. Teklemariam, D.; Azadi, H.; Nyssen, J.; Haile, M.; Witlox, F. Transnational land deals: Toward inclusive governance framework. Land Use Policy 2015, 42, 781-789. [CrossRef]

19. Keping, Y. Governance and Good Governance: A New Framework for Political Analysis. Fudan. J. Hum. Soc. Sci. 2018, 11, 1-8. [CrossRef]

20. Aly, W.O. Bad Governance and Failure of Development Progress in Egypt Causes, Consequences and Remedies. JPAG 2013, 3, 39-60.

21. Jaimurzina, A. Transport Governance: Theoretical and policy perspectives. Infrastruct. Serv. UNI 2018, 365, $1-16$.

22. Beshi, T.D.; Kaur, R. Public trust in local government: Explaining the role of good governance practices. Public Organ. Rev. 2019, 1-14. [CrossRef]

23. Rieseneder, F.B. Good governance: Characteristics, methods and the Australian examples. Transylv. Rev. Adm. Sci. 2008, 4, 26-52.

24. Kalsi, N.S.; Kiran, R.; Vaidhya, C. ICT and Good Governance: A Study of Indian Environment. 2008. E-Governance in Practice. Available online: https://www.csi-sigegov.org/egovernance_pdf/3_10-25.pdf (accessed on 17 September 2019).

25. Essien, E.D. Manifestations of Bad Governance on the Threshold of African Democratic Process and Development. GJDS 2012, 9, 22-42. [CrossRef]

26. Iyad, D. Good Governance for Sustainable Development. Available online: https://mpra.ub.uni-muenchen. de/92544/1/MPRA_paper_92544.pdf (accessed on 27 August 2019).

27. Isaac, L. Corporate governance and organizational performance in the Nigerian banking industry. EJBM 2014, 6, 110-118.

28. Taylor, M.A.; Philp, M. Adapting to climate change-Implications for transport infrastructure, transport systems and travel behavior. Road Transp. Res. 2010, 19, 66-79.

29. Hoffmann, S.; Weyer, J.; Longen, L. Discontinuation of the auto mobility regime? An integrated approach to multi-level governance. Transp. Res. Part A 2017, 103, 391-408.

30. Veeneman, W.; Mulley, C. Multi-level governance in public transport: Governmental layering and its influence on public transport service solutions. Res. Transp. Econ. 2018, 69, 430-437. [CrossRef]

31. Hooghe, L.; Gary, M. Types of multi-level governance. Eur. Integr. Online Pap. EIoP 2011, 5, 1-32.

32. Poku-Boansi, M.; Yaw Asuah, A.; Cobbonah, P.B. Contextualizing transport infrastructure and services in Ghanaian peri-urbanism. Int. Plan. Stud. 2018, 23, 195-209. [CrossRef]

33. Legacy, C.; Curtis, C.; Sturup, S. Is there a good governance model for the delivery of contemporary transport policy and practice? An examination of Melbourne and Perth. Transp. Policy 2012, 19, 8-16. [CrossRef]

34. Mu, R.; de Jong, M. A network governance approach to transit-oriented development: Integrating urban transport and land use policies in Urumqi, China. Transp. Policy 2016, 52, 55-63. [CrossRef]

35. Da Cruz, N.F.; Marques, R.C. Structuring composite local governance indicators. Policy Stud. 2017, 38, 109-129. [CrossRef]

36. Docherty, I.; Marsden, G.; Anable, J. The governance of smart mobility. Transp. Res. Part A 2018, 115, 114-125. [CrossRef]

37. World Bank. Transport Governance Indicators in Sub-Saharan Africa. Available online: http://akb.africaunion.org/auc/handle/AKB/12289 (accessed on 11 June 2019).

38. Tanner, T.; Mitchell, T.; Polack, E.; Guenther, B. Urban Governance for Adaptation: Assessing Climate Change Resilience in Ten Asian Cities; Institute of Development Studies at the University of Sussex: Brighton, UK, 2009; Available online: https://onlinelibrary.wiley.com/doi/pdf/10.1111/j.2040-0209.2009.00315_2.x (accessed on 6 July 2019).

39. Weiss, S.L. A Governance Solution to Prevent the Destruction of Shareholder Value in MEA Transactions; Short Hills Capital Partners: Maplewood, NJ, USA, 2019; Available online: https://papers.ssrn.com/sol3/papers. cfm?abstract_id=3317584 (accessed on 18 August 2019).

40. IPCC. Transport. 2014. Available online: https://www.ipcc.ch/report/ar5/wg3/transport/ (accessed on 9 June 2019).

41. Palmer, D.; Fricska, S.; Wehrmann, B. Towards Improved Land Governance; Land Tenure Working Paper 11; Food and Agriculture Organization of the United Nations: Rome, Italy, 2009.

42. FAO. Good Governance in Land Tenure and Administration; Food and Agriculture Organization of the United Nations: Rome, Italy, 2007. 
43. Franco, J.C. Contemporary discourses and contestations around pro-poor land policies and land governance. J. Agrar. Chang. 2010, 10, 1-32.

44. Srinivas, H. Urban Governance: Need of the Day. 2013. Available online: http://www.gdrc.org/u-gov/needofthe-day.html (accessed on 1 September 2019).

45. Rodríguez-Pose, A.; Di Cataldo, M.; Rainoldi, A. The Role of Government Institutions for Smart Specialisation and Regional Development; European Commission Institute for Prospective Technological Studies: Luxembourg, 2014.

46. Charron, N.; Lapuente, V.; Dykstra, L. Regional Governance Matters: A Study on Regional Variation in Quality of Government within the EU; European Commission Directorate-General for Regional Policy: Brussels, Belgium, 2012.

47. Rodríguez-Pose, A.; Di Cataldo, M. Quality of government and innovative performance in the regions of Europe. J. Econ. Geogr. 2015, 15, 673-706. [CrossRef]

48. Roe, M. Maritime governance and policy-making: The need for process rather than form. Asian J. Shipp. Logist. 2013, 29, 167-186. [CrossRef]

49. Jiang, Y.; Jing, L.; Cai, Y.; Zeng, Q. Analysis of the impacts of different modes of governance on inland waterway transport development on the Pearl River: The Yangtze River Mode vs. the Pearl River Mode. J. Transp. Geogr. 2015, 71, 235-252. [CrossRef]

50. Notteboom, T.; Yang, Q. Port governance in China since 2004: Institutional layering and the growing impact of broader policies. RTBM 2017, 22, 184-200. [CrossRef]

51. Jiang, Y.; Zhou, Z.; Liu, C. The impact of public transportation on carbon emissions: A panelquantile analysis based on Chinese provincial data. ESPR 2019, 26, 4000-4012. [CrossRef]

52. Love, G.; Soares, A.; Püempel, H. Climate Change, Climate Variability and Transportation. Procedia Environ. Sci. 2010, 1, 130-145. [CrossRef]

53. Chapman, L. Transport and climate change: A review. J. Transp. Geogr. 2007, 15, 354-367. [CrossRef]

54. Oswald, M. Literature Review: Transportation Adaptation in Response to Climate Change; University of Delaware, University Transportation Center: Washington, DC, USA, 2009; Available online: http://www.ce.udel.edu/UTC/Presentation\%2009/Literature\%20Review\%20Climate\%20Change\% 20Adaptation\%20_Oswald_090728.pdf (accessed on 25 September 2019).

55. Replogle, M.; Fung, F. Climate Sensitive Transportation Management: Evaluating Alternative Goals for Traffic Growth. In Literature Review: Transportation Adaptation in Response to Climate Change; Oswald, M., Ed.; University of Delaware, University Transportation Center: Washington, DC, USA, 2009; Available online: http://www.ce.udel.edu/UTC/Presentation\%2009/Literature\%20Review\%20Climate\%20Change\% 20Adaptation\%20_Oswald_090728.pdf (accessed on 16 May 2019).

56. Ribeiro, S.S.; Kobayashi, M.; Beuthe, J.; Gasca, D.; Greene, D.S.; Lee, Y.; Muromachi, P.J.; Newton, S.; Plotkin, D.; Sperling, R.; et al. Transport and its infrastructure. In Climate Change 2007: Mitigation; Metz, B., Davidson, O.R., Bosch, P.R., Dave, R., Meyer, L.A., Eds.; Contribution of Working Group III to the Fourth Assessment Report of the Intergovernmental Panel on Climate Change; Cambridge University Press: Cambridge, UK, 2007.

57. Stephenson, J.; Spector, S.; Hopkins, D.; McCarthy, A. Deep interventions for a sustainable transport future. Transp. Res. Part D 2017. [CrossRef]

58. Markolf, S.A.; Hoehne, C.; Fraser, A.; Chester, M.V. Transportation resilience to climate change and extreme weather events-Beyond risk and robustness. Transp. Policy 2019, 74, 174-186. [CrossRef]

59. Holland, S.P.; Mansur, E.T.; Muller, N.Z.; Yates, A.J. Distributional effects of air pollution from electric vehicle adoption. AERE 2019, 6, 65-94. [CrossRef]

60. Bharadwaj, S.; Ballare, S.; Chandel, M. Impact of congestion on greenhouse gas emissions for road transport in Mumbai metropolitan region. Transp. Res. Procedia 2017, 25, 3542-3555. [CrossRef]

61. Meadowcroft, J. Climate Change Governance; Policy Research Working Paper no. WPS 4941; World Bank: Washington, DC, USA, 2009.

62. Lenzen, M.; Dey, C.; Hamilton, C. Climate change. In Handbooks in Transport 4: Handbook of Transport and the Environment; Hensher, D.A., Button, K.J., Eds.; Elsevier: Amsterdam, The Netherlands, 2003; pp. 37-60.

63. Mehrotra, S.; Lefevre, B.; Zimmerman, R.; Gerçek, H.; Jacob, K.; Srinivasan, S. Climate change and urban transportation systems. In Climate Change and Cities: First Assessment Report of the Urban Climate Change Research Network; Rosenzweig, C., Solecki, W.D., Hammer, S.A., Mehrotra, S., Eds.; Cambridge University Press: Cambridge, UK, 2011; pp. 145-177.

64. Goulder, L.H.; Pizer, W.A. The Economics of Climate Change Mitigation; OECD: Paris, France, 2006. 
65. Biyik, C. Smart cities in Turkey: Approaches, advances and applications with greater consideration for future urban transport development. Energies 2019, 12, 2308. [CrossRef]

66. Panday, A.; Bansal, H.O. Green transportation: Need, technology and challenges. Int. J. Glob. Energy Issues 2014, 37, 304-318. [CrossRef]

67. Wang, Q.; Sun, H. Traffic Structure Optimization in Historic Districts Based on Green Transportation and Sustainable Development Concept. Adv. Civ. Eng. 2019, 18. [CrossRef]

68. Kolieb, E.H. Shipping Impaction Climate: A Source with Solutions. Available online: https://www. cleanshipping.org/download/Oceana_Shipping_Report1.pdf (accessed on 14 June 2019).

69. Gilbert, P.; Bows, A.; Starky, R. Shipping and Climate Change: Scope for Unilateral Action. 2010. Available online: http://shippingefficiency.org/sites/shippingefficiency.org/files/Tyndall.pdf (accessed on 8 July 2019).

70. Dessens, O.; Köhler, M.O.; Rogers, H.L.; Jones, R.L.; Pyle, J.A. Aviation and Climate Change. Transp. Policy 2014, 34, 14-20. [CrossRef]

71. Femi, S.A.G. Characterization of current transportation challenges in the federal capital territory, Nigeria. J. Sustain. Dev. 2012, 5, 117-128.

72. Malayath, M.; Verma, A. Activity based travel demand models as a tool for evaluating sustainable transportation policies. Res. Transp. 2013, 38, 45-66. [CrossRef]

73. Valsson, T.; Ulfarsson, G.F. Adaptation and Change with Global Warming. Transp. Res. Record. 2009, 2139, 117-124. [CrossRef]

74. Stern, N. The Stern Review: The Economics of Climate Change. 2006. Available online: www.hmtreasury. gov.uk/d/CLOSED_SHORT_executive_summary.pdf (accessed on 28 June 2019).

75. Lynch, A.; Nicholls, N.; Alexander, L.; Griggs, D. Defining the Impacts of Climate Change on Extreme Events; Commonwealth Government: Canberra, Australia, 2008.

76. Marsden, G.; May, A. Do institutional arrangements make a difference to transport policy and implementation? Lessons for Britain. Environ. Plan. C Gov. Policy 2006, 24, 771-789. [CrossRef]

77. Bauer, A.; Feichtinger, J.; Steurer, R. The Governance of Climate Change Adaptation in Ten OECD Countries: Challenges and Approaches. Discussion Paper 1. 2011. Available online: http://www.wiso.boku.ac.at/ fileadmin/_H73/H732/_TEMP_InFER_DP_11_1__The_Governance_01.pdf (accessed on 17 August 2019).

78. Litman, T. Well Measured: Developing Indicators for Comprehensive and Sustainable Transport Planning; Victoria Transport Policy Institute: Victoria, BC, Canada, 2007.

79. Boelens, L.; Lauwers, D.; Witlox, F. Adaptive Mobility. A New Policy and Research Agenda on Mobility in Horizontal Metropolises; AESOP: Oxford, UK, 2015; p. 215.

80. Semanjski, I.; Bellens, R.; Gautama, S.; Witlox, F. Integrating big data into a sustainable mobility policy 2.0 planning support system. Sustainability 2016, 8, 1142. [CrossRef] 